\title{
Desempenho agronômico do feijoeiro cultivado sob a palhada de plantas de cobertura submetidas à adubação fosfatada
}

Agronomic performance of common bean grown under the straw of cover crops submitted to phosphate fertilization

Rendimiento agronómico del frijol común cultivado bajo la paja de cultivos de cobertura sometidos a fertilización con fosfato

\author{
Érica de Oliveira Araújo \\ ORCID: https://orcid.org/0000-0003-1996-4849 \\ Instituto Federal de Educação, Ciência e Tecnologia de Rondônia, Brasil \\ E-mail: erica.araujo@ifro.edu.br \\ Diogo de Souza Freitas \\ ORCID: https://orcid.org/0000-0002-2626-9564 \\ Instituto Federal de Educação, Ciência e Tecnologia de Rondônia, Brasil \\ E-mail: desouzafreitasdiogo@gmail.com \\ José Vanor Felini Catânio \\ ORCID: https://orcid.org/0000-0001-9400-5555 \\ Instituto Federal de Educação, Ciência e Tecnologia de Rondônia, Brasil \\ E-mail: vanor.catanio@ifro.edu.br \\ Aline Ottes Moreira \\ ORCID: https://orcid.org/0000-0003-3646-7289 \\ Instituto Federal de Educação, Ciência e Tecnologia de Rondônia, Brasil \\ E-mail: alineottesmoreira@gmail.com \\ Jiovane Anderson da Silva Ribeiro \\ ORCID: https://orcid.org/0000-0002-7204-3961 \\ Instituto Federal de Educação, Ciência e Tecnologia de Rondônia, Brasil \\ E-mail: jiovaneribeiro.ifro@gmail.com
}

\begin{abstract}
Resumo
Pesquisas com a inserção de plantas de cobertura na região amazônica ainda são escassas e necessárias para a viabilização do sistema de sucessão, rotação e/ ou plantio direto. Todavia, o presente trabalho teve por objetivo avaliar a produção de biomassa e a absorção de nutrientes por diferentes plantas de cobertura na ausência e presença de adubação fosfatada, bem como constatar os efeitos da palhada sob a produtividade do feijoeiro cultivado em segunda safra, visto que o tipo de palha presente na superfície do solo pode influenciar o manejo das culturas. O experimento foi conduzido em condições de campo, na área experimental do Instituto Federal de Educação, Ciência e Tecnologia de Rondônia, Campus Colorado do Oeste, no munícipio de Colorado do Oeste, RO. O delineamento experimental utilizado foi o de blocos casualizado, arranjados em esquema $4 \times 2 \times 4$, sendo constituídos pelo plantio de quatro espécies de cobertura (Crotalária spectabilis, Crotalária ochroleuca, Mucuna cinza e Feijão guandu), duas doses de fósforo $\left(0\right.$ e $80 \mathrm{~kg} \mathrm{ha}^{-1}$ de $\left.\mathrm{P}_{2} \mathrm{O}_{5}\right)$ e quatro repetições. Os resultados permitiram concluir que as espécies Crotalaria ochroleuca e Crotalaria spectabilis apresentam grande potencial para produção de matéria seca. Os componentes de produção do feijoeiro apresentam melhores resultados em sucessão à adubação verde com a Crotalária ochroleuca e Mucuna Cinza. A dose de fósforo aplicada sob as plantas de cobertura favoreceu além da absorção de $\mathrm{P}$ e K, a absorção de outros nutrientes, tais como $\mathrm{Ca}$ e $\mathrm{Mg}$, que mediante a decomposição e mineralização de seus resíduos puderam atender parte da demanda nutricional da cultura do feijão.
\end{abstract}

Palavras-chave: Phaseolus vulgaris L.; Leguminosas; Resíduo vegetal; Ciclagem de nutrientes; Fósforo; Sustentabilidade.

\begin{abstract}
Research with the insertion of cover crops in the Amazon region is still scarce and necessary for the viability of the system of succession, rotation and/ or no-tillage. However, the present work aimed to evaluate the biomass production and nutrient absorption by different cover crops in the absence and presence of phosphate fertilization, as well as to verify the effects of straw on the productivity of common bean cultivated in the second crop, since the type of straw present in the soil surface can influence crop management. The experiment was conducted in field conditions, in the experimental area of the Federal Institute of Education, Science and Technology of Rondônia, Campus Colorado do
\end{abstract}


Oeste, in the municipality of Western Colorado, RO. The experimental design used was randomized blocks, arranged in a $4 \times 2 \times 4$ scheme, consisting of the planting of four cover species (Crotalária spectabilis, Crotalária ochroleuca, Mucuna cinza and Feijão guandu) two doses of phosphorus (0 and $80 \mathrm{~kg} \mathrm{ha}^{-1}$ of $\left.\mathrm{P}_{2} \mathrm{O}_{5}\right)$ and four replications. The results allowed to conclude that the species Crotalaria ochroleuca and Crotalaria spectabilis have great potential for dry matter production. The production components of the common bean present better results in succession to green fertilization with Crotalaria ochroleuca and Mucuna Cinza. The dose of phosphorus applied under the cover plants favored, in addition to the absorption of $\mathrm{P}$ and $\mathrm{K}$, the absorption of other nutrients, such as $\mathrm{Ca}$ and $\mathrm{Mg}$, which, through the decomposition and mineralization of their residues, were able to meet part of the nutritional demand of the bean crop.

Keywords: Phaseolus vulgaris L.; Legumes; Vegetable residue; Nutrient cycling; Phosphorus; Sustainability.

\section{Resumen}

La investigación con la inserción de cultivos de cobertura en la región amazónica es aún escasa y necesaria para la viabilidad del sistema de sucesión, rotación y/o no labranza. Sin embargo, el presente trabajo tuvo como objetivo evaluar la producción de biomasa y la absorción de nutrientes por parte de diferentes cultivos de cobertura en ausencia y presencia de fertilización con fosfato, así como verificar los efectos de la paja en la productividad del frijol común cultivado en el segundo cultivo, ya que el tipo de paja presente en la superficie del suelo puede influir en el manejo del cultivo. El experimento se llevó a cabo en condiciones de campo, en el área experimental del Instituto Federal de Educación, Ciencia y Tecnología de Rondônia, Campus Colorado do Oeste, en el municipio de Western Colorado, RO. El diseño experimental utilizado fue bloques aleatorizados, dispuestos en un esquema de $4 \times 2 \times 4$, que consiste en la plantación de cuatro especies de cubierta (Crotalária spectabilis, Crotalária ochroleuca, Mucuna cinza y Feijão guandu), dos dosis de fósforo $\left(0\right.$ y $80 \mathrm{~kg} \mathrm{ha}^{-1}$ de $\left.\mathrm{P}_{2} \mathrm{O}_{5}\right)$ y cuatro replicaciones. Los resultados permitieron concluir que las especies Crotalaria ochroleuca y Crotalaria spectabilis tienen un gran potencial para la producción de materia seca. Los componentes de producción del frijol común presentan mejores resultados en sucesión a la fertilización verde con Crotalaria ochroleuca y Mucuna Cinza. La dosis de fósforo aplicada bajo la cubierta de las plantas favoreció, además de la absorción de $\mathrm{P}$ y K, la absorción de otros nutrientes, como ca y mg, que, a través de la descomposición y mineralización de sus residuos, pudieron satisfacer parte de la demanda nutricional del cultivo de frijol.

Palabras clave: Phaseolus vulgaris L.; Legumbres; Residuos vegetales; Ciclo de nutrientes; Fósforo; Sostenibilidad.

\section{Introdução}

O feijão (Phaseolus vulgaris L.) é uma cultura de grande importância econômica e social e, principal fonte de proteína vegetal na alimentação humana em países em desenvolvimento das regiões tropicais e subtropicais. A estimativa de área plantada com feijão na segunda safra 2020/2021 foi de 2.94 milhões de hectares com uma produção de 1.06 milhões de toneladas de feijão (Conab, 2021), o que confere ao País posição de destaque mundial, caracterizando como terceiro maior produtor, ficando atrás de Myanmar e Índia (Faostat, 2021). Na região Norte, o feijão de segunda safra é uma das principais culturas em área plantada, com aproximadamente 61.9 mil hectares, sendo o estado de Rondônia detentor da terceira posição, superado apenas por Tocantins e Acre. Porém, a produtividade média regional da cultura do feijão ainda é insatisfatória, o que se deve em boa parte ao baixo nível tecnológico utilizado nas pequenas e médias propriedades e à baixa fertilidade natural dos solos, que, em sua maioria, apresentam deficiência de nitrogênio $(\mathrm{N})$ e fósforo $(\mathrm{P})$.

Depois do nitrogênio, o P é o segundo elemento mineral essencial de maior importância para a agricultura, sendo que o seu fornecimento representa parte expressiva do custo com implantação de uma lavoura, nas regiões tropicais, por se tratar de solos, em quase sua totalidade, muito intemperizados, ácidos, argilosos e oxídicos, sendo estas características que favorecem a fixação deste elemento pelo solo tornando-o pouco disponível (Silva et al., 2011). A implicação prática disso é que, embora a exigência de $\mathrm{P}$ pelas plantas não seja elevada, grandes quantidades do nutriente devem ser fornecidas nas adubações para promover alguma saturação do solo e originar um excedente que atenda aos requerimentos nutricionais das culturas (Novais; Smyth, 1999).

Assim, considerando a essencialidade do P para as plantas, buscar meios para utilizá-lo eficientemente, a partir de práticas conservacionistas, como o uso de espécies de cobertura, que resultam em aumento na recuperação do $\mathrm{P}$ adicionado ao solo, aumento da produtividade (Albuquerque et al., 2013; Lazaro et al., 2013; Carvalho et al., 2015, Aker et a., 2016), 
manutenção do equilíbrio do sistema, possibilidades de sequestro de carbono no solo e ciclagem de nutrientes, revelam-se uma alternativa promissora para a região amazônica, visto que os resíduos das plantas de cobertura contêm quantidades consideráveis de P, e que mediante sua mineralização poderão atender boa parte da demanda das culturas (Oliveira et al., 2002; Andrade et al., 2003).

Por conseguinte, pesquisas com a inserção de plantas de cobertura na região amazônica, em especial no estado de Rondônia ainda são escassas e necessárias para a viabilização do sistema de sucessão, rotação e/ ou plantio direto, com premissas ao aprofundamento do conhecimento científico e desenvolvimento de processo tecnológico destinado à produção agrícola regional. Todavia, o presente trabalho teve por objetivo avaliar a produção de biomassa e a absorção de nutrientes por diferentes plantas de cobertura na ausência e presença de adubação fosfatada, bem como constatar os efeitos da palhada sob a produtividade do feijoeiro cultivado em segunda safra, visto que o tipo de palha presente na superfície do solo pode influenciar o manejo das culturas.

\section{Material e Métodos}

O experimento foi conduzido em condições de campo, na área experimental do Instituto Federal de Educação, Ciência e Tecnologia de Rondônia, Campus Colorado do Oeste, no munícipio de Colorado do Oeste, RO, cujas coordenadas geográficas são $13^{\circ} 06^{\prime} \mathrm{S}$ e $60^{\circ} 29^{\prime} \mathrm{W}$, com altitude média de 407 metros. O clima segundo a classificação de Köppen é do tipo Awa, tropical quente e úmido com duas estações bem definidas. Dados médios de temperatura e precipitação pluviométrica durante a condução do experimento foram obtidos do banco de dados do Instituto Nacional de Meteorologia (Figura 1). A caracterização química do solo foi realizada na camada de 0-10 cm e 10-20 cm, em amostras coletadas antes da instalação do experimento e são apresentados na Tabela 1. A análise granulométrica da area experimental na profundidade de 0-10 cm apresentou $343 \mathrm{~g} \mathrm{dm}^{-3}$ de argila, $479 \mathrm{~g} \mathrm{dm}^{-3}$ de areia e $178 \mathrm{~g} \mathrm{dm}^{-3}$ de silte.

Por tratar-se de pesquisa continuada, a correção do solo foi realizada, trinta dias antes da primeira semeadura de plantas de cobertura (ano agrícola 2019), com base nos resultados da análise do solo na camada de 0-10 cm, utilizando calcário dolomítico (PRNT 97\%), com o objetivo de elevar a saturação por bases a 60\%. A partir desta correção, as premissas experimentais foram para cultivo mínimo, sem revolvimento do solo, com cobertura permanente e semeadura na palha.

Figura 1. Precipitação $(\mathrm{mm})$ e temperatura $\left({ }^{\circ} \mathrm{C}\right)$ médias mensais, registradas na estação metereológica do Instituto Nacional de Meteorologia, no período de outubro de 2020 a junho de 2021.

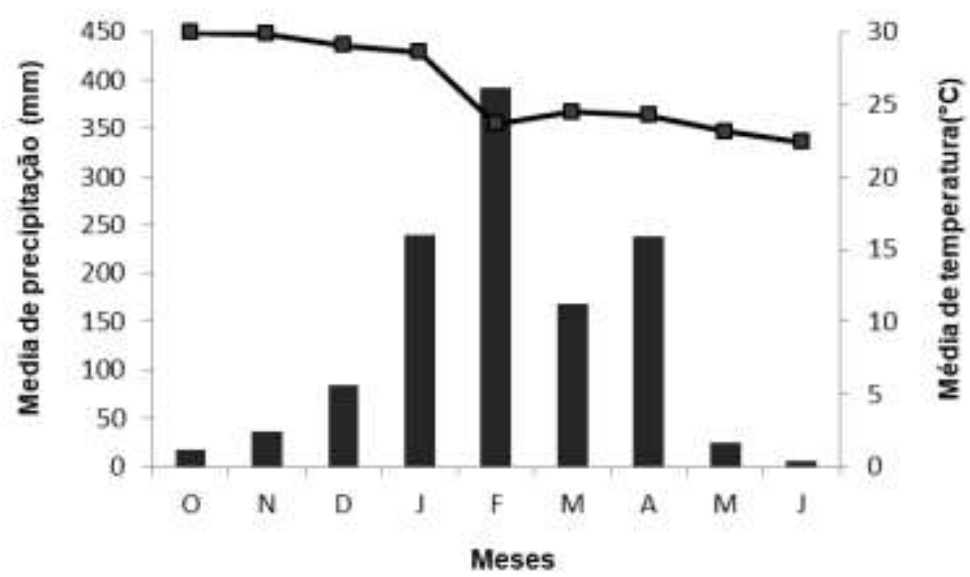

Fonte: Autores. 
Tabela 1. Atributos químicos do solo antes da instalação do experimento em diferentes profundidades.

\begin{tabular}{|c|c|c|c|c|c|c|c|c|c|c|c|c|}
\hline Amostragem & \multicolumn{2}{|c|}{$\mathrm{g} / \mathrm{dm}^{-3}$} & $\begin{array}{c}\mathrm{pH} \\
\mathrm{CaCl}_{2}\end{array}$ & $\begin{array}{l}\mathrm{P} \\
\mathrm{m}\end{array}$ & $\mathrm{mg} / \mathrm{dm}^{-3}$ & $\mathrm{Ca}$ & $\mathrm{Mg}$ & $\mathrm{H}+\mathrm{Al}$ & $\begin{array}{l}\mathrm{Al} \\
\mathrm{c} / \mathrm{d}\end{array}$ & SB & CTC & $\begin{array}{c}\mathrm{V} \\
(\%)\end{array}$ \\
\hline $0-10 \mathrm{~cm}$ & 11.4 & 4.62 & 4.9 & 4 & 81.9 & 29 & 8 & 30 & 1 & 40 & 70 & 57 \\
\hline $10-20 \mathrm{~cm}$ & 5.3 & 3.08 & 5.0 & 1 & 58.5 & 36 & 4 & 25 & 1 & 41 & 66 & 62 \\
\hline
\end{tabular}

Fonte: Autores.

O delineamento experimental utilizado foi o de blocos casualizado, arranjados em esquema $4 \times 2 \times 4$, sendo constituídos pelo plantio de quatro espécies de cobertura (Crotalária spectabilis, Crotalária ochroleuca, Mucuna cinza e Feijão guandu), na ausência e presença de fósforo (0 e $80 \mathrm{~kg} \mathrm{ha}^{-1}$ de $\left.\mathrm{P}_{2} \mathrm{O}_{5}\right)$, tendo como fonte solúvel de $\mathrm{P}_{2} \mathrm{O}_{5}$ o superfosfato triplo $\left(45 \% \mathrm{P}_{2} \mathrm{O}_{5}\right)$, e quatro repetições, perfazendo o total 32 unidades experimentais.

Na primeira etapa, os sulcos de plantio para as plantas de cobertura foram abertos mecanicamente na profundidade de $5 \mathrm{~cm}$, de acordo com espaçamento determinado, e a semeadura realizada manualmente. Os diferentes gastos de sementes adotados foram baseados em recomendações técnicas para as diferentes plantas de cobertura. Cada unidade experimental foi composta por 8 linhas de 5 metros de comprimento, espaçadas em $0.45 \mathrm{~m}$ entre linhas e $0.20 \mathrm{~m}$ entre plantas. Consideraram-se como parcela útil as seis linhas centrais, excluindo-se $0.5 \mathrm{~m}$ de cada extremidade da parcela. Por ocasião do pleno florescimento, as plantas de cobertura foram dessecadas com utilização do herbicida glifosato (1.920 g ha ${ }^{-1}$ do i.a.) e, em seguida, manejadas com auxilio roçadeira manual na altura de $0.05 \mathrm{~m}$ em relação à superfície do solo, visando à uniformização da área. No entanto, antes da dessecação foi avaliada a produção de massa seca da parte aérea das diferentes plantas de cobertura. Para determinação da massa seca foi utilizado um quadro $(0.50 \mathrm{~m}$ x $0.50 \mathrm{~m})$ visando demarcar a área da parcela, na qual foi coletada a amostra (rente ao solo), sendo, esta, pesada, e levada para estufa de circulação forçada de ar, a $65^{\circ} \mathrm{C}$, até atingir peso constante, determinando-se a massa seca. Os teores de macronutrientes na massa seca da parte aérea foram determinados de acordo com a metodologia descrita em Embrapa (2009).

Na segunda etapa, após 45 dias da dessecação das plantas de cobertura, sobre a palhada foi realizada a semeadura mecanizada do feijão-comum, cultivar BRS Estilo (de grão comercial carioca, arquitetura de planta semiereta, hábito de crescimento indeterminado tipo II), em espaçamento de $0.80 \mathrm{~m}$ entre linhas, com população de plantas de 212500 mil/plantas/hectare, considerando como parcela útil duas linhas centrais, excluindo-se $0.50 \mathrm{~m}$ de cada extremidade da parcela.

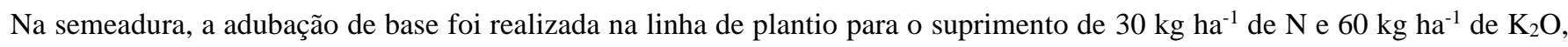
respectivamente. Todos os demais tratos culturais foram realizados conforme preconizado para a cultura do feijoeiro.

Por ocasião do pleno florescimento (50\% das plantas em floração) e da maturidade fisiológica da cultura coletou-se uma planta por unidade experimental para determinação dos teores de macronutrientes na parte aérea. Todo o material vegetal coletado foi acondicionado em sacos de papel e secos em estufa com circulação forçada de ar, à temperatura de $65^{\circ} \mathrm{C}$, por 72 horas, sendo posteriormente moídos e submetidos à digestão sulfúrica e digestão nitro-perclórica, utilizando a metodologia descrita em Embrapa (2009). Os componentes de produção, tais como número de vagens por planta, número de grãos por vagem, número de grãos por planta, peso de mil grãos e produtividades de grãos foram obtidos a partir das mensurações de cinco plantas da área útil da parcela, na maturidade fisiológica. A produtividade foi determinada pelo peso de grãos da área útil em quilogramas, com correção para $13 \%$ de umidade, transformando os dados para kg ha ${ }^{1}$.

Os dados foram submetidos ao teste de normalidade (Shapiro Wilk) e análise de variância, sendo os efeitos entre as diferentes plantas de cobertura e adubação fosfatada, bem como suas correlações, avaliados pelo teste de Tukey a nível de 5\% de probabilidade utilizando-se o programa estatístico Sisvar. 


\section{Resultados e Discussão}

Os resultados evidenciaram efeitos significativos da interação dupla entre palhada e adubação fosfatada para a variável produção de massa seca e teores de P e K nas diferentes plantas de cobertura (Tabela 2), e para os componentes de produção do feijoeiro (Tabela 3).

O cultivo de Crotalaria ochroleuca e Crotalaria spectabilis proporcionaram os melhores resultados para produção de massa seca, 13.42 t.ha ${ }^{-1}$ e 13.88 t.ha ${ }^{-1}$, respectivamente, não diferindo estatisticamente entre si na ausência de adubação fosfatada; na presença de adubação fosfatada $\left(80 \mathrm{~kg} /\right.$ ha de $\left.\mathrm{P}_{2} \mathrm{O}_{5}\right)$ a espécie Feijão guandu destacou-se com uma produção de massa seca na ordem de 17.40 t.ha ${ }^{-1}$, diferindo estatisticamente $(\mathrm{p}<0.05)$ das demais espécies; enquanto que a menor produção de massa seca foi constatada pela espécie Mucuna cinza tanto na presença quanto na ausência de adubação fosfatada (Tabela 2). Tal produção de massa seca pelas espécies de crotalárias deve-se a estrutura morfológica de caule lenhoso que, de acordo com o estádio de desenvolvimento da planta, apresenta um elevado teor de água resultando desta forma em um aumento na quantidade de massa fresca da planta, além de um grande desenvolvimento das plantas (Bettiol et al., 2015). Essa produção e posterior acréscimo de massa seca no solo podem causar alterações significativas nas características físicas e químicas do solo, na manutenção e/ou elevação dos teores de matéria orgânica do solo, e na manutenção da temperatura do solo, além de favorecer o desenvolvimento e a produtividade de espécies agrícolas em cultivos subsequentes (Araújo et al., 2021; Andrade Neto et al., 2008; Boer et al., 2008).

De forma geral, a quantidade de massa vegetal fornecida pelas plantas de cobertura apresentou valores superiores aos que têm sido apontados como quantidade mínima ideal de adição de matéria em um sistema de rotação de culturas, de maneira que a cobertura do solo se mantenha adequada, com valor de 6t/ha/ano de palhada, conforme citado por Alvarenga et al. (2001), sendo a média geral de produtividade da massa seca de 10 t/ha e 13 t/ha nas doses de $0 \mathrm{~kg} / \mathrm{ha} \mathrm{de} \mathrm{P}_{2} \mathrm{O}_{5} 80$ e $80 \mathrm{~kg} / \mathrm{ha}$ de $\mathrm{P}_{2} \mathrm{O}_{5}$, respectivamente, resultado este superior à quantidade mínima, indicando desta forma uma boa cobertura do solo. Estes resultados corroboram integralmente aos encontrados por Araújo et al., (2021), no qual o cultivo de Crotalaria spectabilis e Crotalaria ochroleuca na safra 2019/2020 apresentaram produtividades superiores de massa seca em sistema de cultivo sem adubação fosfatada; e corroboram parcialmente aos resultados obtidos por Pereira et al., (2017), que observaram baixa produção de massa seca para Mucuna.

Apesar da alta capacidade de produção de massa seca pela espécie Crotalaria ochroleuca na ausência de adubação fosfatada, verifica-se que a capacidade em absorver e acumular P nas folhas em pleno florescimento foi inferior tanto na ausência quanto na presença de adubação fosfatada, reforçando a premissa que essas plantas têm a capacidade de desenvolver estratégias fisiológicas para conviver com a baixa disponibilidade de P; enquanto que a capacidade em absorver e acumular nas folhas em pleno florescimento $\mathrm{K}$ foi superior (Tabela 2). Todavia, pode-se constatar resposta significativa das espécies de plantas de cobertura quanto à adubação fosfatada $\left(80 \mathrm{~kg} / \mathrm{ha}\right.$ de $\left.\mathrm{P}_{2} \mathrm{O}_{5}\right)$, visto que todas as espécies apresentaram incrementos nas produções de massa seca e acúmulos de $\mathrm{P}$ e K com a dose aplicada, podendo contribuir com elevada incorporação de nutrientes posteriormente à decomposição da biomassa. Resultados semelhantes foram obtidos por Araújo et al., (2021) estudando a ciclagem de nutrientes por diferentes plantas de cobertura em ambiente amazônico. 
Tabela 2. Desdobramento da interação dupla significativa para produção de massa seca e teores de fósforo e potássio na parte aérea de diferentes plantas de cobertura submetidas a adubação fosfatada.

\begin{tabular}{ccc}
\hline & Produção de Massa seca $(\mathrm{kg} / \mathrm{ha})$ & $80 \mathrm{~kg} / \mathrm{ha} \mathrm{de} \mathrm{P}_{2} \mathrm{O}_{5}$ \\
Plantas de cobertura & $0 \mathrm{~kg} / \mathrm{ha} \mathrm{de} \mathrm{P}_{2} \mathrm{O}_{5}$ & $15411.00 \mathrm{bA}$ \\
\hline C. ochroleuca & $13424.00 \mathrm{aB}$ & $15632.00 \mathrm{bA}$ \\
C. spectabilis & $13888.00 \mathrm{aB}$ & $5125.00 \mathrm{cA}$ \\
Mucuna cinza & $4892.00 \mathrm{cA}$ & $17403.00 \mathrm{aA}$ \\
Feijão guandu & $11598.00 \mathrm{bB}$ & $80 \mathrm{~kg} / \mathrm{ha} \mathrm{de}_{2} \mathrm{O}_{5}$ \\
\hline & Teor de P $(\mathrm{g} / \mathrm{kg})$ & $1.37 \mathrm{cA}$ \\
Plantas de cobertura & $0 \mathrm{~kg} / \mathrm{ha} \mathrm{de} \mathrm{P}_{2} \mathrm{O}_{5}$ & $1.68 \mathrm{aA}$ \\
\hline C. ochroleuca & $1.16 \mathrm{cB}$ & $1.47 \mathrm{bA}$ \\
C. spectabilis & $1.57 \mathrm{aB}$ & $1.56 \mathrm{aA}$ \\
Mucuna cinza & $1.33 \mathrm{bB}$ & $80 \mathrm{~kg} / \mathrm{ha} \mathrm{de} \mathrm{P}_{2} \mathrm{O}_{5}$ \\
Feijão guandu & $1.56 \mathrm{aB}$ & $20.36 \mathrm{aA}$ \\
\hline Plantas de cobertura & Teor de K $(\mathrm{g} / \mathrm{kg})$ & $19.92 \mathrm{aA}$ \\
\hline C. ochroleuca & $0 \mathrm{~kg} / \mathrm{ha} \mathrm{de} \mathrm{P}_{2} \mathrm{O}_{5}$ & $18.82 \mathrm{bA}$ \\
Mucuna cinza & $14.51 \mathrm{aB}$ & $18.20 \mathrm{bA}$ \\
\hline
\end{tabular}

As letras minúsculas separam as médias dentro de cada coluna e as maiúsculas separam as médias dentro de cada linha. Letras iguais não diferem entre si pelo teste Tukey a 5\% de probabilidade. Fonte: Autores.

Para aos parâmetros produtivos da cultura do feijão, a palhada de Crotalaria ochroleuca e Mucuna cinza na ausência de $\mathrm{P}$ proporcionou diferença estatística significativa $(\mathrm{p}<0.05)$ para número de grãos por vagem, número de grãos por planta, peso de mil grãos, e, por conseguinte, na produtividade de grãos de feijão (Tabela 3). Verifica-se que apenas a palhada dessas plantas de cobertura sem qualquer adição de fósforo e mediante decomposição rápida (baixa relação C/N) foram capazes de fornecer nutriente a cultura subsequente, de forma a favorecer o seu crescimento e desenvolvimento, uma vez que no fornecimento de $80 \mathrm{~kg} /$ ha de $\mathrm{P}_{2} \mathrm{O}_{5}$ apesar de ter apresentado valores superiores entre as palhadas das plantas de cobertura, não diferiu estatisticamente entre si, conforme mostra a Tabela 3.

Os melhores resultados de peso de mil grãos e produtividade de grãos de feijão foram obtidos nos tratamentos com palhada de Crotalaria ochroleuca e Mucuna cinza; e justamente nestes tratamentos, foram constatados os maiores e menores valores de produção de massa seca das coberturas, respectivamente (Tabela 2 e Tabela 3). Quando observado o efeito da interação entre doses de $\mathrm{P}$ e a palhada das plantas de cobertura, todas as variáveis responderam significativamente e positivamente ao fornecimento de P (Tabela 3). Nota-se incremento médio na produtividade de grãos de feijão em resposta a palhada das plantas de cobertura adubada com $80 \mathrm{~kg} / \mathrm{ha}$ de $\mathrm{P}_{2} \mathrm{O}_{5}$, na ordem de 47\%, ou seja, a associação dessas plantas com o sistema de manejo do solo pode resultar em ganhos na produtividade das culturas, em função da melhoria da qualidade do solo, sendo eficiente a recomendação de utilização de plantas de cobertura antecessora da cultura do feijão e permitindo inferir que a capacidade de produção de está diretamente relacionada com as condições edafoclimáticas. 
Tabela 3. Desdobramento da interação dupla significativa entre palhada de plantas de cobertura e adubação fosfatada para os componentes de produção do feijoeiro comum.

\begin{tabular}{|c|c|c|}
\hline \multicolumn{3}{|c|}{ Número de grãos/vagem } \\
\hline Plantas de cobertura & $0 \mathrm{~kg} / \mathrm{ha}$ de $\mathrm{P}_{2} \mathrm{O}_{5}$ & $80 \mathrm{~kg} / \mathrm{ha}$ de $\mathrm{P}_{2} \mathrm{O}_{5}$ \\
\hline C. ochroleuca & $6.42 \mathrm{aA}$ & $6.30 \mathrm{aA}$ \\
\hline C. spectabilis & $5.47 \mathrm{bB}$ & $6.40 \mathrm{aA}$ \\
\hline Mucuna cinza & $6.20 \mathrm{aA}$ & $6.65 \mathrm{aA}$ \\
\hline Feijão guandu & $4.82 \mathrm{cB}$ & $6.55 \mathrm{aA}$ \\
\hline \multicolumn{3}{|c|}{ Número de grãos/planta } \\
\hline Plantas de cobertura & $0 \mathrm{~kg} / \mathrm{ha}$ de $\mathrm{P}_{2} \mathrm{O}_{5}$ & $80 \mathrm{~kg} / \mathrm{ha}$ de $\mathrm{P}_{2} \mathrm{O}_{5}$ \\
\hline C. ochroleuca & $106.01 \mathrm{aB}$ & $135.45 \mathrm{aA}$ \\
\hline C. spectabilis & $90.33 \mathrm{bcB}$ & $137.60 \mathrm{aA}$ \\
\hline Mucuna cinza & $102.30 \mathrm{abB}$ & $142.97 \mathrm{aA}$ \\
\hline Feijão guandu & $79.61 \mathrm{cB}$ & $140.82 \mathrm{aA}$ \\
\hline \multicolumn{3}{|c|}{ Peso de 1000 grãos } \\
\hline Plantas de cobertura & $0 \mathrm{~kg} / \mathrm{ha}$ de $\mathrm{P}_{2} \mathrm{O}_{5}$ & $80 \mathrm{~kg} / \mathrm{ha}$ de $\mathrm{P}_{2} \mathrm{O}_{5}$ \\
\hline C. ochroleuca & $337.68 \mathrm{aB}$ & $467.47 \mathrm{aA}$ \\
\hline C. spectabilis & $292.90 \mathrm{bB}$ & $389.52 \mathrm{bA}$ \\
\hline Mucuna cinza & $341.16 \mathrm{aB}$ & $442.47 \mathrm{aA}$ \\
\hline Feijão guandu & $274.22 \mathrm{bB}$ & $344.08 \mathrm{bA}$ \\
\hline \multicolumn{3}{|c|}{ Produtividade de grãos (kg/há) } \\
\hline Plantas de cobertura & $0 \mathrm{~kg} / \mathrm{ha}$ de $\mathrm{P}_{2} \mathrm{O}_{5}$ & $80 \mathrm{~kg} / \mathrm{ha}$ de $\mathrm{P}_{2} \mathrm{O}_{5}$ \\
\hline C. ochroleuca & $990.18 \mathrm{aB}$ & $1590.18 \mathrm{aA}$ \\
\hline C. spectabilis & $895.06 \mathrm{bcB}$ & $1533.06 \mathrm{aA}$ \\
\hline Mucuna cinza & $974.50 \mathrm{aB}$ & $1534.50 \mathrm{aA}$ \\
\hline Feijão guandu & $844.18 \mathrm{bB}$ & $1526.02 \mathrm{aA}$ \\
\hline
\end{tabular}

As letras minúsculas separam as médias dentro de cada coluna e as maiúsculas separam as médias dentro de cada linha. Letras iguais não diferem entre si pelo teste Tukey a 5\% de probabilidade. Fonte: Autores.

Quanto aos aspectos nutricionais, no desdobramento da interação dupla entre a palhada das plantas de cobertura e adubação fosfatada foram observados efeitos significativos para os teores de $\mathrm{P}$ e $\mathrm{Mg}$ na parte aérea do feijoeiro em pleno florescimento e na maturidade fisiológica (Tabela 4); enquanto que os teores de $\mathrm{K}, \mathrm{Ca}$ e $\mathrm{Mg}$ no feijoeiro foram influenciadas apenas pela palhada das diferentes plantas de cobertura ou doses de $\mathrm{P}$, restringindo-se a análise dos efeitos isolados.

A palhada da espécie Crotalaria ochroleuca proporcionou o maior acumulo de $\mathrm{K}$ em plantas de feijão no pleno florescimento, diferindo estatisticamente $(\mathrm{p}<0.05)$ apenas da espécie Mucuna cinza (Figura 2), o que permite afirmar que a espécie Crotalaria ochroleuca foi mais eficiente quanto à ciclagem de nutriente e disponibilidade de K a plantas de feijão, havendo correlação positiva entre o teor de $\mathrm{K}$ nos tecidos da espécie Crotalaria ochroleuca no florescimento (Tabela 1) e os teores de $\mathrm{K}$ nos tecidos das plantas de feijão no florescimento. É importante ressaltar que teores de $\mathrm{K}$ tende a ser mais altos no pleno florescimento das plantas e reduções são observadas com o avanço das fases fenológicas. Isso ocorre porque o K tem alta mobilidade no floema (Marcschner, 2002) e a maior parte é absorvida pelas plantas durante a fase de crescimento vegetativo, visto o papel fundamental do nutriente na fotossíntese e síntese de carboidratos (Yamada, 1987) e ativação de enzimas para diversos processos fisiológicos. 
Figura 2. Teor de $\mathrm{K}$ em plantas de feijão no pleno florescimento cultivado sob a palhada de diferentes plantas de cobertura. *Letras iguais não diferem entre si pelo teste Tukey a $5 \%$ de probabilidade.

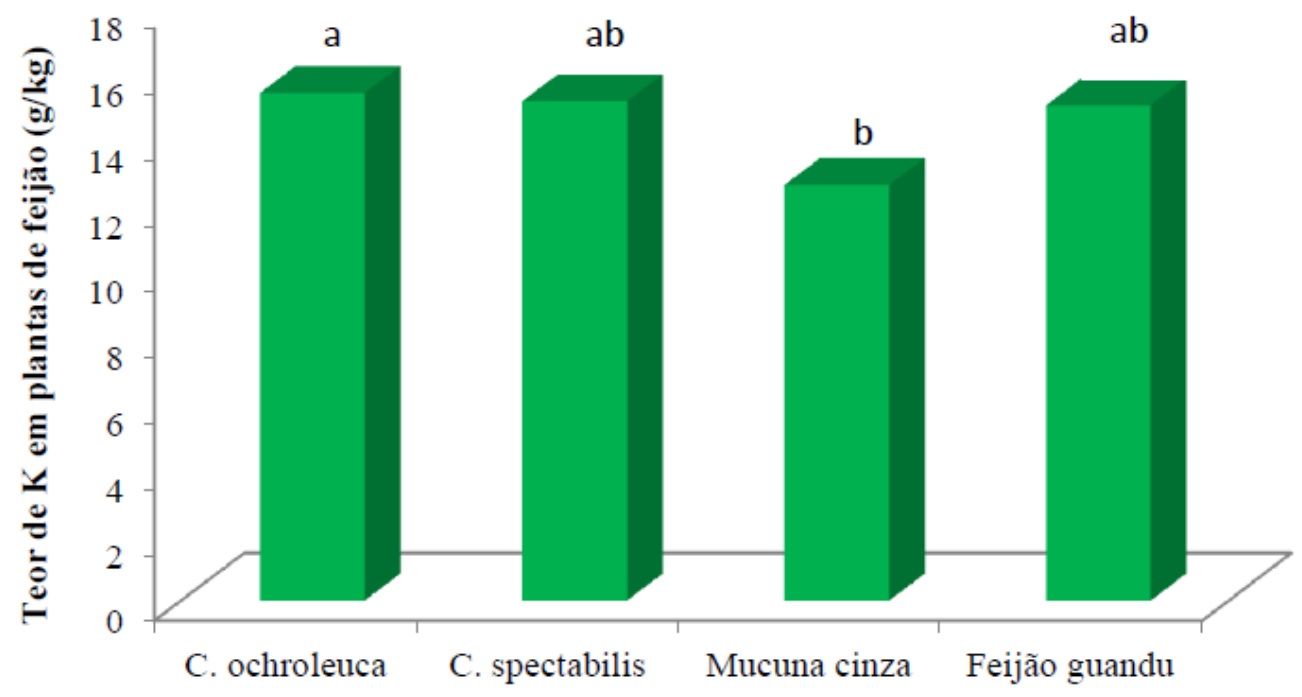

Fonte: Autores.

Já a adubação fosfatada de $80 \mathrm{~kg} / \mathrm{ha}^{-1}$ de $\mathrm{P}_{2} \mathrm{O}_{5}$ aplicada sob as plantas de cobertura exerceram efeito crescente e significativo $(\mathrm{p} \leq 0.05)$ sobre os teores de $\mathrm{Ca}$ e $\mathrm{Mg}$ nos tecidos de plantas de feijão no pleno florescimento e na maturidade fisiológica, quando comparado à ausência da adubação fosfatada (Figura 3). A dose de fósforo aplicada sob as plantas de cobertura favoreceu além da absorção de $\mathrm{P}$, a absorção de outros nutrientes, tais como Ca e Mg, que mediante a decomposição e mineralização de seus resíduos puderam atender parte da demanda nutricional da cultura do feijão. Os teores de Ca e Mg nos tecidos do feijoeiro no pleno florescimento e na presença de adubação fosfatada $\left(80 \mathrm{~kg} / \mathrm{ha}^{-1} \mathrm{de} \mathrm{P}_{2} \mathrm{O}_{5}\right)$, foram de $16.57 \mathrm{~g} / \mathrm{kg}$ e $4.72 \mathrm{~g} / \mathrm{kg}$, respectivamente, enquanto que os teores de $\mathrm{Ca}$ e $\mathrm{Mg}$ nos tecidos do feijoeiro na maturidade fisiológica foram de $4.14 \mathrm{~g} / \mathrm{kg}$ e $13.88 \mathrm{~g} / \mathrm{kg}$ respectivamente, constatando correlação inversa quanto aos teores do nutrientes, e estando dentro da faixa considerada adequada por Malavolta et al. (2006), que varia entre 15-20 g kg-1 de Ca e 4-7 g kg-1 de Mg. O cálcio tem baixa mobilidade na planta razão pela qual se acumula nas folhas, sem poder ser redistribuído para outras partes da planta antes da queda das folhas (Epstein \& Bloom, 2006; Marschner, 2002), e o feijoeiro apresenta queda de folhas durante a senescência. Além disso, a insolubilidade dos compostos de cálcio da planta e sua localização na célula explicam, em parte, a limitada redistribuição ao longo do ciclo da planta. Já o magnésio, embora seja considerado um nutriente móvel (Marschner, 2002), segundo Malavolta (2006), é comum encontrar maior concentração de magnésio em folhas mais velhas do que em folhas jovens, permitindo o comportamento proporcionalmente inverso ao $\mathrm{Ca}$. 
Figura 3. Teores de $\mathrm{Ca}$ e $\mathrm{Mg}$ em plantas de feijão no pleno florescimento (A) e na maturidade fisiológica (B) em resposta a palhada de plantas de cobertura submetidas a adubação fosfatada. *Letras iguais não diferem entre si pelo teste Tukey a $5 \%$ de probabilidade.
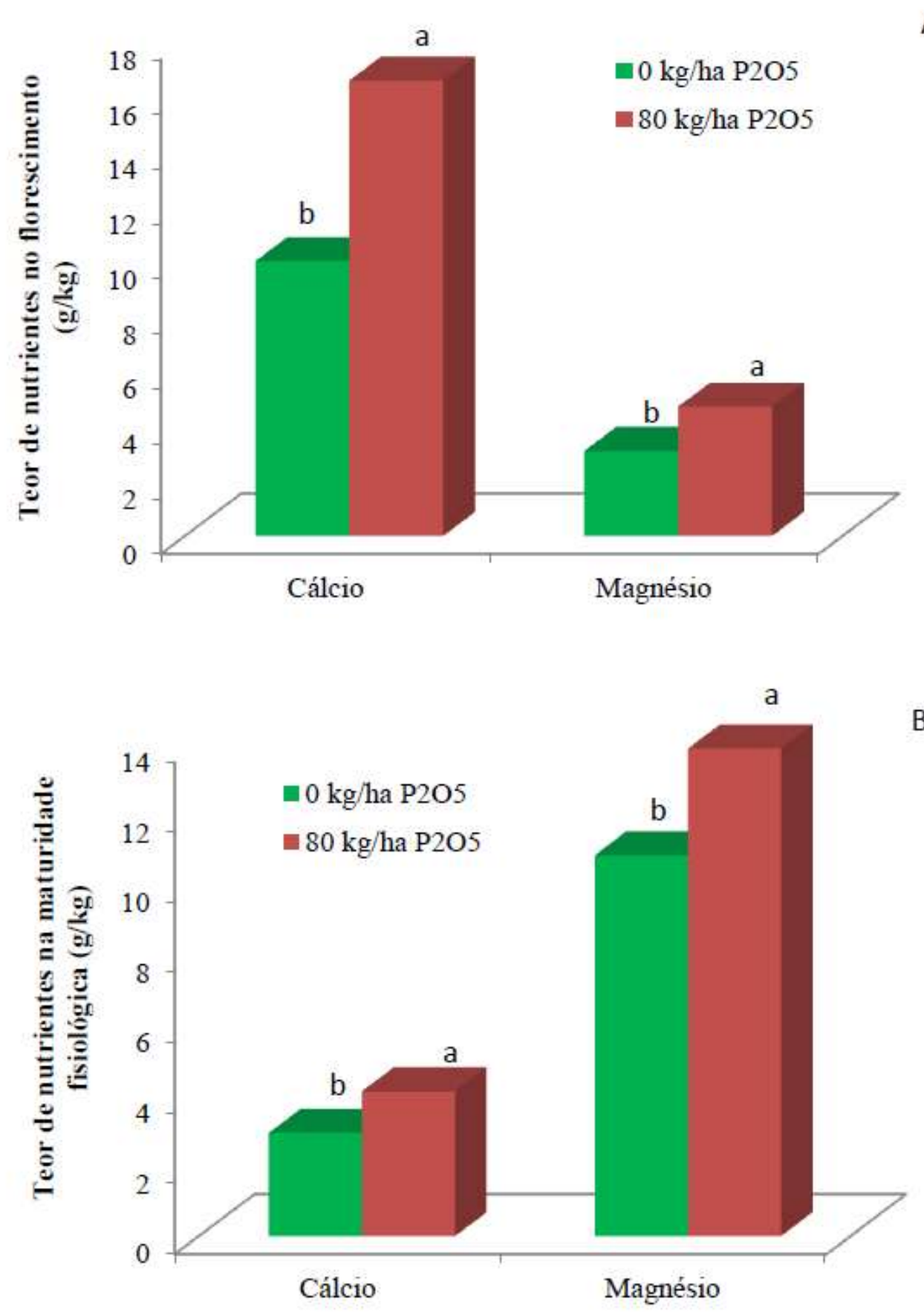

Fonte: Autores. 
Na comparação das espécies de plantas de cobertura em cada dose de fósforo, verificou-se superioridade nos teores de P em plantas de feijão no pleno florescimento e na maturidade fisiológica quando cultivado sob a palhada de Crotalaria. spectabilis e Feijao-guandu (Tabela 4). Ao analisarmos o efeito da ausência de adubação fosfatada sob os teores de P no florescimento e na maturidade fisiológica do feijoeiro, as espécies supracitadas destacam-se quando comparadas com as demais espécies, mesmo não havendo diferença estatística entre as demais espécies. Isso evidencia que mesmo sob deficiência de P no solo as plantas de cobertura desenvolveram o sistema radicular, visando aumentar a capacidade de absorção de P, visto a baixa mobilidade deste elemento no solo, e contribuiu com a ciclagem de nutrientes para cultura subsequente, mantendo razoável produção de massa seca e acumulo de $\mathrm{P}$ nos tecidos, conforme mostra tabela 2. Enquanto que para os teores de $\mathrm{Mg}$ em plantas de feijão no pleno florescimento e na maturidade fisiológica a resposta significativa foi na presença de adubação fosfatada não havendo diferença estatística entre as espécies de plantas de cobertura (Tabela 4).

Tabela 4. Desdobramento da interação dupla significativa para teores de fósforo (P) e magnésio ( $\mathrm{Mg}$ ) no pleno florescimento e na maturidade fisiológica de plantas de feijão cultivadas sob a palhada de diferentes plantas de cobertura submetidas à adubação fosfatada.

\begin{tabular}{|c|c|c|}
\hline \multicolumn{3}{|c|}{ Teor de $\mathrm{P}(\mathrm{g} / \mathrm{kg})$ florescimento } \\
\hline Plantas de cobertura & $0 \mathrm{~kg} / \mathrm{ha}$ de $\mathrm{P}_{2} \mathrm{O}_{5}$ & $80 \mathrm{~kg} / \mathrm{ha}$ de $\mathrm{P}_{2} \mathrm{O}_{5}$ \\
\hline C. ochroleuca & $1.95 \mathrm{bB}$ & $2.49 \mathrm{abA}$ \\
\hline C. spectabilis & $2.14 \mathrm{abB}$ & $2.78 \mathrm{aA}$ \\
\hline Mucuna cinza & $1.93 \mathrm{bB}$ & $2.57 \mathrm{abA}$ \\
\hline Feijão guandu & $2.47 \mathrm{aB}$ & $2.76 \mathrm{aA}$ \\
\hline \multicolumn{3}{|c|}{ Teor de $\mathrm{Mg}(\mathrm{g} / \mathrm{kg})$ florescimento } \\
\hline Plantas de cobertura & $0 \mathrm{~kg} / \mathrm{ha}$ de $\mathrm{P}_{2} \mathrm{O}_{5}$ & $80 \mathrm{~kg} / \mathrm{ha}$ de $\mathrm{P}_{2} \mathrm{O}_{5}$ \\
\hline C. ochroleuca & $2.14 \mathrm{aA}$ & $3.76 \mathrm{bA}$ \\
\hline C. spectabilis & $2.62 \mathrm{aB}$ & $4.26 \mathrm{aA}$ \\
\hline Mucuna cinza & $2.75 \mathrm{aA}$ & $4.32 \mathrm{aA}$ \\
\hline Feijão guandu & $2.85 \mathrm{aB}$ & $4.99 \mathrm{aA}$ \\
\hline \multicolumn{3}{|c|}{ Teor de $\mathrm{P}(\mathrm{g} / \mathrm{kg})$ na maturidade fisiológica } \\
\hline Plantas de cobertura & $0 \mathrm{~kg} / \mathrm{ha}$ de $\mathrm{P}_{2} \mathrm{O}_{5}$ & $80 \mathrm{~kg} / \mathrm{ha}$ de $\mathrm{P}_{2} \mathrm{O}_{5}$ \\
\hline C. ochroleuca & $0.34 \mathrm{aB}$ & $0.47 \mathrm{cA}$ \\
\hline C. spectabilis & $0.40 \mathrm{aB}$ & $0.82 \mathrm{bA}$ \\
\hline Mucuna cinza & $0.39 \mathrm{aA}$ & $0.46 \mathrm{cA}$ \\
\hline Feijão guandu & $0.36 \mathrm{aB}$ & $1.13 \mathrm{aA}$ \\
\hline \multicolumn{3}{|c|}{ Teor de $\mathrm{Mg}(\mathrm{g} / \mathrm{kg})$ na maturidade fisiológica } \\
\hline Plantas de cobertura & $0 \mathrm{~kg} / \mathrm{ha}$ de $\mathrm{P}_{2} \mathrm{O}_{5}$ & $80 \mathrm{~kg} / \mathrm{ha}$ de $\mathrm{P}_{2} \mathrm{O}_{5}$ \\
\hline C. ochroleuca & $9.92 \mathrm{aB}$ & $12.89 \mathrm{aA}$ \\
\hline C. spectabilis & $10.30 \mathrm{aB}$ & $12.78 \mathrm{aA}$ \\
\hline Mucuna cinza & $11.82 \mathrm{aA}$ & $11.07 \mathrm{aA}$ \\
\hline Feijão guandu & $11.23 \mathrm{aB}$ & $12.32 \mathrm{aA}$ \\
\hline
\end{tabular}

As letras minúsculas separam as médias dentro de cada coluna e as maiúsculas separam as médias dentro de cada linha. Letras iguais não diferem entre si pelo teste Tukey a 5\% de probabilidade. Fonte: Autores.

\section{Conclusões}

As espécies Crotalaria ochroleuca e Crotalaria spectabilis apresentam grande potencial para produção de matéria seca. Os componentes de produção do feijoeiro apresentam melhores resultados em sucessão à adubação verde com a Crotalária ochroleuca e Mucuna Cinza. A dose de fósforo aplicada sob as plantas de cobertura favoreceu além da absorção de 
P e K, a absorção de outros nutrientes, tais como Ca e $\mathrm{Mg}$, que mediante a decomposição e mineralização de seus resíduos puderam atender parte da demanda nutricional da cultura do feijão.

\section{Agradecimentos}

Os autores agradecem a Fundação Agrisus, ao Instituto Federal de Rondônia e ao Departamento de Pesquisa, Inovação e Pós-graduação do Campus Colorado do Oeste pela disponibilização de recursos, taxa de bancada e bolsa de iniciação científica.

\section{Referências}

Aker, A. M., Passos, A. M. A., Marcolan, A. L., Santos, F. C., Cipriani, H. N., \& Vargas, L. A. (2016). Plantas de cobertura sobre os atributos agronômicos do milho na região sudoeste da Amazônia. Revista Brasileira de Milho e Sorgo, 15(3), 531-542. https://doi.org/10.18512/1980-6477/rbms.v15n3p531-542

Albuquerque, A. W., Santos, J. R., Filho, G. M. \& Reis, L. S. (2013). Plantas de cobertura e adubação nitrogenada na produção de milho em sistema de plantio direto. Revista Brasileira de Engenharia Agrícola e Ambiental, 17(7), 721-726. https://doi.org/10.1590/S1415-43662013000700005

Andrade Neto, R. C., Góes, G. B., Miranda, N. O., Filho, E. T. D., \& Filho, F. S. T. P. (2008). Adubação verde: uma alternativa sustentável para o Brasil. Revista Verde, 3(1), 16-20. https://dialnet.unirioja.es/servlet/articulo?codigo=7476761

Andrade, F. V., Mendonça, E. S., Alvarez, V. V. H., \& Novais, R. F. (2003). Adição de ácidos orgânicos e húmicos em. Latossolos e adsorção de fosfato. Revista Brasileira de Ciência do Solo, 22(6), 1003-1011. https://doi.org/10.1590/S0100-06832003000600004

Araújo, E., Ribeiro, J., Venturim, D., Catânio, J., Macieski Neto, V., Freitas, D., Moreira, A., De Paula, N., Costa, J., Costa, W., \& Santos, K. (2021). Absorption of nutrients and chemical reconditioning of red latosol by cover plants cultivated in Amazon environment. Australian Journal Crop Science, 15, (1), 145-155. 10.21475/ajcs.21.15.01.2964.

Bettiol, J. V. T., Pedrinho, A., Merloti, L. F., Bossolani, J. W., \& Sá, M. E. (2015). Plantas de Cobertura, Utilizando Urochloa ruziziensis Solteira e em Consórcio com Leguminosas e seus Efeitos Sobre a Produtividade de Sementes do Feijoeiro. Uniciências, 19(1), 3-10.

https://doi.org/10.17921/1415-5141.2015v19n1p\%25p

Boer, C. A., Assis, R. L., Silva, G. P., Braz, A. J. B. P., Barroso, A. L. L, Filho, A. C., \& Pires, F. R. (2008). Biomassa, decomposição e cobertura do solo ocasionada por resíduos culturais de três espécies vegetais na região centro-oeste do Brasil. Revista Brasileira de Ciência do Solo, 32(2), 843-851. https://doi.org/10.1590/S0100-06832008000200038

Carvalho, A. M., Coser, T. R., Rein, T. A., Dantas, R. A., Silva, R. R., \& Souza, K. W. (2015). Manejo de plantas de cobertura na floração e na maturação fisiológica e seu efeito na produtividade do milho. Pesquisa Agropecuária Brasileira, 50(7), 551-561. 10.1590/S0100-204X2015000700005

Conab (2021). Acompanhamento da Safra Brasileira de Grãos 2020/2021: Oitavo Levantamento, Maio/2021, Companhia Nacional de Abastecimento. Brasília, CONAB, 8(8), 115.

Empresa Brasileira de Pesquisa Agropecuária. (2009). Manual de análises químicas de solos, plantas e fertilizantes. (2a ed,), Embrapa Informação Tecnológica, 627.

FAOSTAT. (2021). Crops. http://www.fao.org/faostat/en/\#data/QC

Lázaro, R. L., Costa, A. C. T., Silva, K. F., Sarto, M. V. M., \& Duarte Júnior, J. B. (2013). Produtividade de milho cultivado em sucessão à adubação verde. Pesquisa Agropecuária Tropical, 43(1), 10-17. https://www.scielo.br/j/pat/a/YzmWkcJj6c4b5XFkHqsb9GF/?lang=pt\&format=pdf

Malavolta, E. (2006). Manual de nutrição mineral de plantas. Agronômica Ceres.

Marschner, H. (2002). Mineral nutrition of higher plants. Academic.

Novais, R. F., \& Smyth, T. J. (1999). Fósforo em solo e planta em condições tropicais. UFV, DPS, 399 p.

Pereira, A. P., Schoffel, A., Koefender, J., Camera, J. N., Golle, D. P., \& Horn, R. C. (2017). Ciclagem de nutrients por plantas de cobertura de verão. Revista de Ciências Agrárias, 40(4), 799-807. https://doi.org/10.19084/RCA17065

Silva, T. O., Furtini Neto, A. E., Carneiro, L. F., \& Paludo, V. (2011). Plantas de cobertura submetidas a diferentes fontes de fósforo em solos distintos. Semina: Ciências Agrárias, 32(4), 1315-1326. https://www.redalyc.org/pdf/4457/445744110010.pdf

Yamada, T. (1987). Potássio: Dinâmica e disponibilidade no solo. In: Fernandes, F. M., Nascimento, V. M. (ed.). Curso de atualização em fertilidade do solo. Campinas, Fundação Cargill. 